\title{
The solution of social problems from the perspective of philosophy of education.
}

\begin{abstract}
The purpose of this paper is to explore educational philosophy approaches to solving social problems. These approaches are also considered from the perspectives of some popular denominations and branches of philosophy of education that discuss social problems. This paper stressed that social problems are not to be seen only from this mechanism; it is also upon the basis on how the problems occurred or to avoid them through wise evaluation. Malaysia is a country which is in the process of paradigm shift and experiencing rapid technological development that will bring it to the same level as the other developing countries. However, globalization and modernization have brought both positive and negative elements to the society. These two main elements need to be faced as a challenge in modern life. Nevertheless, development as a positive value can still be accepted as long as it does not conflict with religion, culture, and society's norms. However, during this development, social problems increase and collapse Malaysia's social structure. Many teenagers lose their life focus. Modernization and globalization had changed their behavior, lifestyle, and their thinking. Development has been misused by them and they became involved in unhealthy activities, ruined their future and their parents and indirectly destroyed state's expectations of them. Many of the teenagers have become involved in hedonistic culture, refuse to think, and do not seriously face the realities of life. Their loss of focus makes them a burden to their country.
\end{abstract}

Keyword: Philosophy of education; Branches of philosophy; Social problems. 